\title{
Perhitungan Laju Aliran Fluida Kritis Untuk Mempertahankan Tekanan Reservoir Pada Sumur Ratu Di Lapangan Kinantan
}

\author{
Calculation of Flowing Rate Critice to Maintain Reservoir Pressure On Ratu Well In \\ Kinantan field
}

\author{
Ali Musnal \\ Jurusan Teknik Perminyakan Fakultas Teknik Universitas Islam Riau \\ Jl. Kaharuddin Nasution 113 Pekanbaru-28284 \\ ulpti@yahoo.co.id
}

\begin{abstract}
Abstrak.
Sumur yang telah diproduksikan fluida reservoirnya, sehubungan dengan perjalanan waktu lamanya produksi sumur tersebut, sudah dipastikan laju produksinya akan berkurang, hal ini disebabkan salah satu parameternya adalah turunnya tekanan reservoir. Tekanan reservoir mempunyai peranan aktif untuk mendorong fluida dari reservoir kepermukaan. Banyak cara yang telah dilakukan untuk mempertahankan Tekanan reservoir antara lain dengan menginjeksikan air kelapangan minyak tersebut melalui sumur injeksi, hal ini terkenal dengan istilah water Flooding. Dan pada penelitian ini untuk mempertahankan tekanan reservoir suatu sumur adalah dengan melakukan produksi sumur tersebut dibawah laju aliran kritis. Untuk mendapatkan laju alir kritis dan menetukan panjang interval perforasi suatu sumur dapat dihitung dengan menggunakan beberapa metode. Antara lain yaitu metode Chaperon, Chierici, Meyer, Gardner and Pirson. Sebagai aplikasi dari penelitian ini diambil data sumur Ratu dilapangan Kinantan yang merupakan salah satu lapangan minyak didaerah Riau.
\end{abstract}

Kata-kata kunci: Laju Alir Fluida, Tekanan reservoir dan Laju Airan Kritis.

\begin{abstract}
Wells which have produced fluid reservoir, in connection with the passage of time the length of the production wells, one would expect the rate of production will be reduced, and this is one of the parameters is the pressure drop in the reservoir. Reservoir pressure has an active role to push the fluid from the reservoir to the surface. Many ways have been done to maintain reservoir pressure by injecting water, among others, the oil spaciousness through injection wells, it is known by the term water flooding. And in this study to maintain reservoir pressure of the well is to do with the production of the well below the critical flow rate. To obtain the critical flow rate and determine the length of a well perforation interval can be calculated using several methods. Among others, the method Chaperon, Chierici, Meyer, Gardner and Pirson. As an application of this research field are taken well data Kinantan Queen which is one of the oil field area of Riau.
\end{abstract}

Kata Kunci: Rate Fluida, KritisRate, Reservoir Pressure. 


\section{PENDAHULUAN.}

Untuk pengangkatan Minyak dari reservoir, proses produksi memegang peranan penting di dalam suatu industri perminyakan. Proses produksi adalah mencari cara yang optimal untuk memproduksikan/ mengangkat fluida yang ada di dalam reservoir sampai kepermukaan. Hal ini bukanlah mudah namun mencakup kegiatan yang cukup kompleks. Oleh karena itu perlu dioptimalkan dalam perolehan produksi minyak agar hasil-nya memberikan profit yang maksimal. Salah satu dari usaha tersebut adalah dengan mempertahankan tekanan reservoir, sehingga diharapkan minyak yang ada direservoir sebagian besar bisa terangkat kepermukaan. Apabila hal ini tidak diperhatikan kemungkinan yang akan terjadi tenaga pendorong sudah habis sedangkan minyak masih banyak tersisa di dalam reservoir. Banyak upaya dan cara yang dapat dilakukan untuk mempertahankan Tekanan reservoir pada saat produksi diantaranya dengan mengontrol laju alir produksi. Laju alir kritis dapat dihitung dengan menggunakan beberapa metode. Metode tersebut antara lain , (1) Chaperon (2) Chierici, (3) Meyer, Gardner and Pirson. Dari hasil perhitungan laju aliran kritis ke 3 metoda ini Peneliti akan membahas untuk dijadikan rekomandasi dari penelitian ini.

\section{METODA PENELITIAN.}

Didalam penelitian ini penulis melakukan kegiatan terstruktur mulai dari studi literatur, studi lapangan, pengambilan data dan mengaplikasikan metoda yang digunakan untuk menghitung besarnya laju aliran kritis.Dari hasil perhitungan yang didapat diantara metoda yang digunakan dilakukan evaluasi. Hasil evaluasi ini dapat direkomandasikan pada User sebagai stakholder dari lapangan tersebut.

\section{TEORI DASAR}

\subsection{Kurva IPR}

Kurva Inflow Performance Relationship (IPR) adalah kurva yang menggambarkan kemampuan suatu sumur untuk berproduksi, yang dinyatakan dalam bentuk hubungan antara laju produksi $(q)$ terhadap tekanan alir dasar sumur $(P w f)$.

\section{Dalam persiapan pembuatan kurva} IPR terlebih dahulu harus diketahui Productivity Index $(P I)$ sumur tersebut, yang merupakan gambaran secara kwalitatif mengenai kemampuan suatu sumur untuk berproduksi. 


\subsubsection{Produktivity Index (PI)}

Produktiuvity Indeks merupakan indeks yang digunakan untuk menyatakan kemampuan suatu sumur untuk berproduksi pada suatu kondisi tertentu, atau dinyatakan sebagai perbandingan antara laju produksi suatu sumur pada suatu harga tekanan alir dasar sumur (Pwf) tertentu dengan perbedaan tekanan dasar sumur pada keadaan statik (Ps) dan tekanan dasar sumur pada saat terjadi aliran (Pwf), dinyatakan dalam stock tank barrel per day. Secara matematis bentuknya dapat dituliskan sebagai berikut:

$$
P I=J=\frac{q_{o}}{P_{s}-P_{w f}}
$$

$$
\text { PI = Productivity Index, } \mathrm{bpd} / \mathrm{psi}
$$

Q = Laju Produksi, bbl/day

Ps = Tekanan Statistik Dasar Sumur, Psi

Pwf $=$ Tekanan Alir Dasar Sumur, Psi

Secara teoritis persamaan (3-1) dapat didekati oleh persamaan radial dari Darcy untuk fluida homogen, incompressible dan horizontal. Dengan demikian untuk aliran minyak saja berlaku hubungan :

Selanjutnya jika fluida yang mengalir merupakan kombinasi dari fluida fasa satu dan fluida dua fasa, yaitu terjadi pada kondisi tekanan reservoir $(\operatorname{Pr})$ lebih besar dari pada tekanan bubble point $(\mathrm{Pb})$ dan tekanan alir dasar sumur (Pwf) sudah mengalami penurunan hingga lebih kecil dari $\mathrm{Pb}$. Aliran satu fasa yaitu $\mathrm{qb}$, terjadi mulai dari Pr hingga $\mathrm{Pb}$, dan aliran fluida dua fasa yaitu q, akan terjadi mulai dari $\mathrm{Pb}$ hingga Pwf.

Dalam persiapan pembuatan kurva IPR untuk kondisi satu fasa lebih dahulu harus diketahui hubungan sebagai berikut ini, dimana PI (J) pada saat Pwf $=0$ Psi adalah:

$q \max =J(\operatorname{Pr}-P w f))$

Jika tes dilakukan pada kondisi dibawah tekanan gelembung minyak $(\mathrm{Pb})$, maka $\mathrm{J}$ dapat ditentukan dengan persamaan berikut:

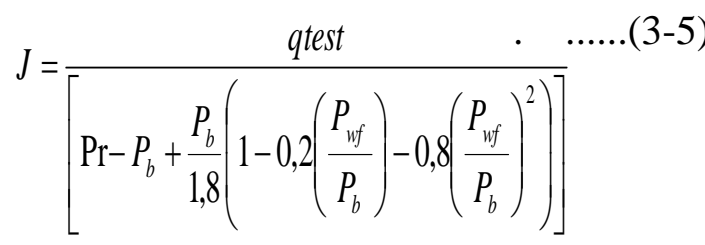

dan apabila test dilakukan pada saat Pwf > $\mathrm{Pb}$, maka:

$J=\frac{q_{\text {test }}}{\operatorname{Pr}-P w f_{\text {test }}}$

Semua penentuan harga PI yang telah dikemukakan di atas dapat dilakukan bila data-data dari hasil tes yang telah tersedia.

\subsubsection{Kurva IPR Satu Fasa}


Kurva IPR untuk satu fasa akan membentuk suatu garis linear dengan harga PI yang konstan untuk setiap harga Pwf. Hal ini terjadi apabila tekanan reservoir $(P r)$ lebih besar dari tekanan gelembung minyak $(P b)$.

Aliran fluida pada tekanan reservoir lebih besar dari pada tekanan gelembung atau PI konstan dan Ps juga konstan, maka variabelnya adalah laju produksi $(q)$ dan tekanan aliran di dasar sumur $(P w f)$ kurva IPR dapat dibuat persamaan :

$$
P_{w f}=P_{r}-\frac{q}{P I}
$$

Pada persaman (3-6) terlihat bahwa Pwf dan laju produksi mempunyai hubungan yang linier, yang disebut Inflow Performance Relationship, yang menggambarkan reaksi-reaksi reservoir bila ada perbedaan tekanan didalamnya.Berdasarkan anggapan diatas, maka bentuk garis dari persamaan (3-6) adalah merupakan garis lurus seperti yang terlihat pada Gambar 3.1

Apabila sudut $\mathrm{OAB}$ adalah $\theta$, maka :

$$
\tan \theta=\frac{\mathrm{OB}}{\mathrm{OA}}=\frac{\mathrm{PI} \times \mathrm{Ps}}{\mathrm{Ps}}=\mathrm{PI} \text {. }
$$

Untuk membuat kurva IPR diperlukan data-data sebagai berikut :

- Laju produksi $(q)$

- Tekanan alir dasar sumur $(P w f)$
- Tekanan statik atau tekanan reservoir $(P r)$

Ketiga data tersebut diperoleh dari hasil uji sumur serta test produksi dari sumur yang bersangkutan.

Untuk menentukan laju aliran kritis digunakan beberapa metode antara lain :

\section{Metode Chaperon}

Chaperon mengembangkan persamaan laju alir kritis pada reservoir yang terjadi gas coning, persamaannya sebagai berikut :

$$
q_{o}=\frac{3,486 \times 10^{-5}}{B_{o}} \frac{k_{h} h^{2}}{\mu_{o}}[\Delta \rho] q_{c}^{*}
$$

Untuk U.S. oil field units persamaan diatas menjadi :

$$
q_{o}=\frac{4,888 \times 10^{-4}}{B_{o}} \frac{k_{h} h^{2}}{\mu_{o}}[\Delta \rho] q_{c}^{*}
$$

\section{HASIL PERHITUNGAN DAN PEMBAHASAN}

\subsection{Data Sumur}

Diketahui data sebuah sumur adalah sebagai berikut :

Tekanan reservoir $\quad$ : 2190 Psi

Jaju Produksi : : $300 \mathrm{Bfpd}$

Tebal Lapisan Produktif $\quad: 65 \mathrm{ft}$

Top Penforasi $\quad: 31,815 \mathrm{ft}$

Tekanan Alir dasar Sumur $\quad$ : 1600 Psi

Permeabilitas Minyak $\quad: 23 \mathrm{mD}$ 


$\begin{array}{ll}\text { Permeabilitas Horisontal } & : 100 \mathrm{mD} \\ \text { Permeabilitas Vertikal } & : 400 \mathrm{mD} \\ \text { Jari - Jari Pengurasan Sumur } & : 950 \mathrm{ft} \\ \text { Jari - Jari Sumur } & : 1,667 \mathrm{ft} \\ \text { Faktorvolume formasi } & : 1,307 \mathrm{bbl} / \mathrm{STB} \\ \text { Visc Oil } & : 0,667 \mathrm{cp} \\ \text { Densitas Oil } & : 0,48 \mathrm{lb} / \mathrm{ft}^{3} \\ \text { Densitas Water } & : 1 \mathrm{lb} / \mathrm{ft}^{3}\end{array}$

\subsection{Membuat Kurva IPR}

$$
\begin{aligned}
P I & =\frac{Q}{P_{r}-P_{w f}} \\
P I & =\frac{300}{2190-1600} \\
& =0.5
\end{aligned}
$$

Penentukan nilai Pwf untuk masingmasing Q asumsi

\section{- Asumsi I}

Asumsikan laju alir $(\mathrm{Q}=0 \mathrm{Bpd})$

$$
\begin{aligned}
P_{w f} & =P_{r}-\frac{Q}{P I} \\
P w f & =2190-\frac{0}{0.5} \\
& =2190 \quad \text { Psi }
\end{aligned}
$$

- Asumsi II

Asumsikan laju alir (Q = $100 \mathrm{Bpd})$

$$
\begin{aligned}
P_{w f} & =P_{r}-\frac{Q}{P I} \\
P w f & =2190-\frac{100}{0.5} \\
& =1990 \mathrm{Psi}
\end{aligned}
$$

- Untuk harga Pwf yang lain dapt dilihat pada tabel 4.1 dibawah.

Menentukan Laju Alir Maksimum (Qmax), pada saat Pwf $=0$ Psi.

$$
\begin{aligned}
\text { Qmaks } & =0.5 \mathrm{bfpd} / \mathrm{psi}(2190 \mathrm{Psi}-0) \\
& =1095 \mathrm{BFPD}
\end{aligned}
$$

Tabel 4.1 Hasil Perhitungan Pwf

\begin{tabular}{|c|c|}
\hline Q asumsi & Pwf \\
\hline$($ Bpd $)$ & $($ Psi $)$ \\
\hline 0 & 2190 \\
\hline 100 & 1990 \\
\hline 250 & 1690 \\
\hline 500 & 1190 \\
\hline 750 & 690 \\
\hline 1000 & 190 \\
\hline 1095 & 0 \\
\hline
\end{tabular}

Dari hasil tabel kita plot antara laju produksi dengan Tekanan alir dasar sumur, maka didapat kurva IPR untuk sumur Ratu lapangan Kinantan. 


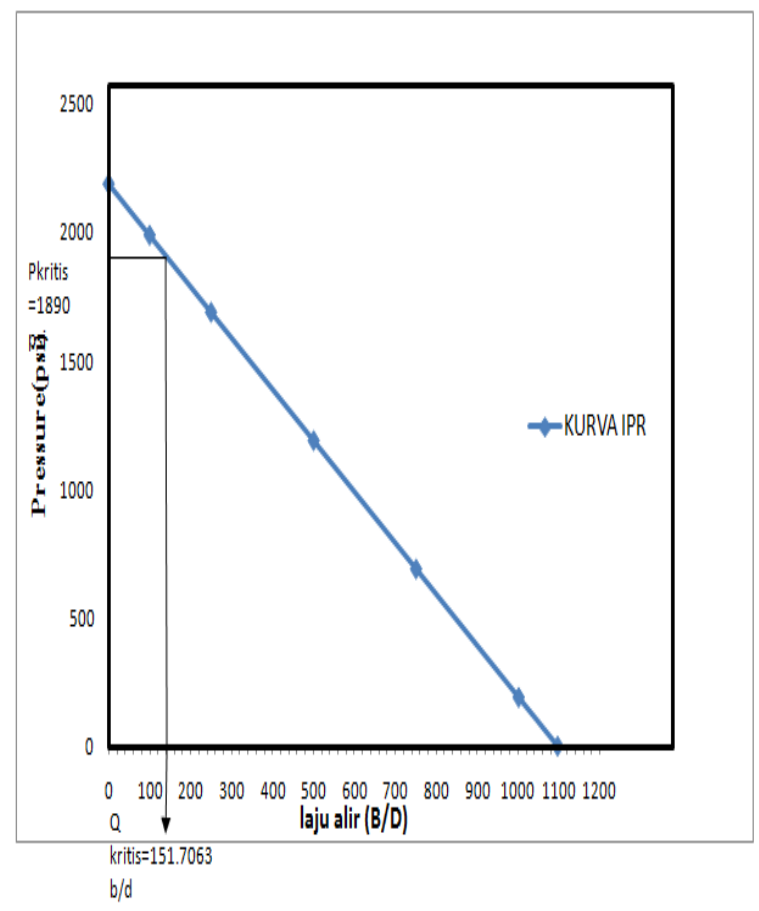

Gambar 1. Kurva IPR dan Laju airan Kritis.

\subsection{Menentukan Laju Alir Kritis}

Untuk menentukan laju aliram krits pada penelitian ini dipergunaan metoda Chaperon perhitungannya sebagai berikut :

Langkah 1 Menghitung nilai qc

Langkah 2 Menghitung $\alpha "$

$$
\begin{aligned}
\alpha^{\prime \prime} & =\left(r_{e} / h\right)\left(k_{v} / k_{h}\right)^{0,5} \\
& =(950 / 80)(400 / 100)^{0,5} \\
& =23,75
\end{aligned}
$$

Langkah 3 Menghitung $\mathrm{q}_{\mathrm{c}}$

$$
\begin{aligned}
q_{c}^{*} & =0,7311+\left(1,943 / \alpha^{\prime \prime}\right) \\
& =0,7311+(1,943 / 23,75)
\end{aligned}
$$

$$
=0,813
$$

Langkah 4 Menghitung qo

$$
\begin{gathered}
q_{o}=\frac{4,888 \times 10^{-4}}{B_{o}} \frac{k_{h} h^{2}}{\mu_{o}}[\Delta \rho] q_{c}^{*} \\
q_{o}=\frac{4,888 \times 10^{-4}}{1,307} \frac{100 \times 80^{2}}{0,667}[0,52] 0,813 \\
\mathrm{q}_{\mathrm{o}}=151,7063 \mathrm{STB} / \text { day }
\end{gathered}
$$

Dari hasil perhitungan diatas dapat dilihat untuk sumur Ratu lapangan Kinantan diperoleh besarnya laju alira kritis Qo 151,706 STb/day, dengan tekanan reservoir sebesar 1890 Psi. Didalam teori sudah dijelaskan bahwa supaya kita dapat mempertahankan Tekanan reservoir dalam jangka waktu lama, maka laju alir minyak yang diproduksikan tidak boleh melewati laju aliran kritis, dan apabila ada kecendrungan tekan reservoir menurun dapat juga dilakukan dengan water flooding yaitu dengan menginjeksikan air ke sumur injeksi.

\section{KESIMPULAN}

Dari hasil penelitian ini penulis dapat menyimpulkan sebagai berikut :

1. Berdasarkan hasil perhitungan besarnya laju produksi maksimum dari sumur Ratu 1095 BFPD.dan laju alir kritis sebesar 151.706 BFPD. 
2. Untuk mempertahankan tekanan reservoir dari sumur Ratu, maka laju produksi yang dihasilkan tidak boleh melewati 152,706 BFPD.

3. Apa bila sudah terjadi kecendrungan tekanan reservoir menurun, maka dapat juga dilakukan dengan water flooding.

\section{DAFTAR PUSTAKA}

1. Paper SPE 87046 presented at the SPE Asia Pasific Conference on Integrated Modelling for asset management, 2004.Wibowo, W., BP Indonesia, Permadi P., Mardisewojo, P and Sukarno, P., Institut Teknologi bandung, Behaviour of Water Cresting and production Performance of Horzontal Water Drive reservoir: A Scaled Model Study,.

2. Craft, B. C. and Hawkins, M. F.: Applied Petroleum Reservoir Engineering, $2^{\text {nd }} \boldsymbol{E d}$., Revised by R. E. Terry, Prentice-Hall Inc., Englewood Cliffs, NJ, 1991.

3. Amyx,

J.W. Bass,

D.M.,Jr.,Whitting,R.L;

Reservoir
Engineering

Physical

Properties"; Mc.Graw Hill Book

Co.Inc.;NewYork;1960

4. Burjik E. J.,;'Propeties of Petroleum Reservoir Fluid", John Wiley and Sons Inc., New York, 1961

5. Mc.Cain, WD.Jr., "The Properties of Petroleum Fluid", Petroleum Publishing Company, Tusla. Missisipi State, 1973.

6.

\section{DAFTAR SIMBOL}

Dimana :

$q_{o} \quad=$ Laju alir kritis (laju produksi minyak maksimum tanpa terjadi coning), STB/hari

$\mu_{o} \quad=$ Viscositas minyak, $\mathrm{cp}$

Bo = Faktor volume formasi minyak, $\mathrm{RB} / \mathrm{stb}$

$=$ Densitas minyak, gm/cc

$=$ Densitas air, $\mathrm{gm} / \mathrm{cc}$

$=$ Permeabilitas horisontal, $\mathrm{md}$

$k_{v} \quad=$ Permeabilitas vertikal

$h \quad=$ Ketebalan kolom minyak, $\mathrm{ft}$

$r_{e} \quad=$ Jari-jari pengurasan, $\mathrm{ft}$

$r_{w} \quad=$ Jari-jari sumur, $\mathrm{ft}$

$\Delta \rho=\rho_{w}-\rho_{o}$, perbedaan densitas, $\mathrm{ft}$

$\mathrm{J}=$ Productivity index, $\mathrm{bbl} / \mathrm{hari} / \mathrm{psi}$ 


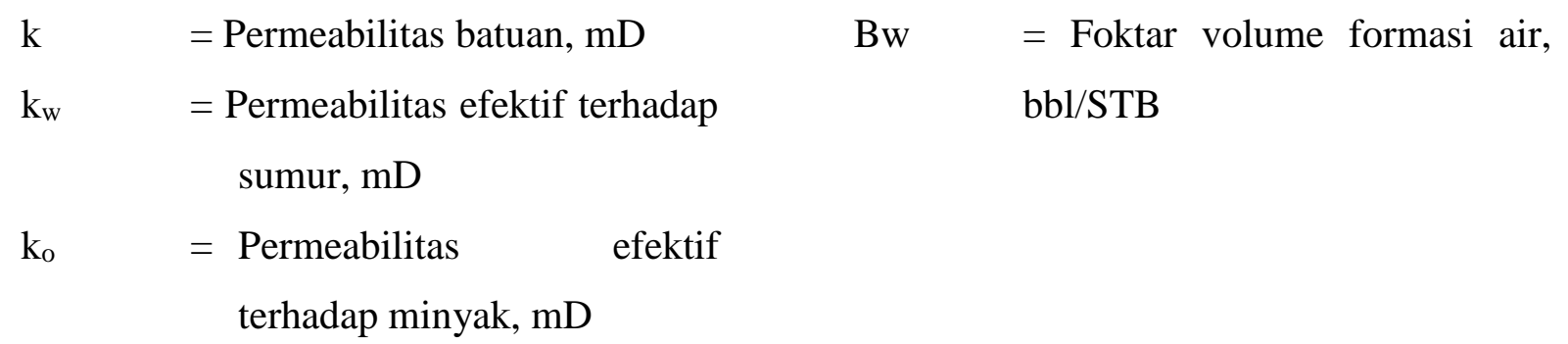

